\title{
AS MOSCAS SINANTRÓPICAS COMO FERRAMENTAS PARA EDUCAÇAO AMBIENTAL: CIRCUITO CIÊNCIAS E SAÚDE AMBIENTAL
}

Leonice Seolin Dias ${ }^{1}$

Raquel Henrique ${ }^{2}$

Raul Borges Guimarães ${ }^{3}$

Resumo: O presente relato de caso vem apresentar os resultados da experiência vivida pelos pesquisadores do Laboratório de Biogeografia e Geografia da UNESP, quando da participação do evento Semana do Meio Ambiente, no município de Teodoro Sampaio-SP em junho de 2013. O laboratório tem como objetivo estudar a correlação da saúde coletiva aos padrões espaçiais de condição de vida, cabendo-lhe o estudo sobre as populações de moscas sinantrópicas enquanto parâmetro do impacto das transformações do território na saúde ambiental. Os trabalhos de campo realizados no município com o intuito de investigar a frequência de moscas e existência de estruturas parasitárias nestes insetos levantaram certa curiosidade por parte dos cidadãos, principalmente dos estudantes. Em vista disso, organizou-se uma atividade denominada Circuíto Ciências para que se pudesse realizar a contrapartida à sociedade, esclarecendo sobre as pesquisas realizadas, atentando-se para a importância ecológica do estudo das moscas como bioindicador ambiental. As seguintes atividades compuseram o circuito: diálogos e aplicação de questionário, apresentação de vídeo, visualização em placa de petri das

${ }^{1}$ Doutoranda em Geografia - Universidade Estadual Paulista (UNESP) de Presidente Prudente, SP Email: nseolin@gmail.com

${ }^{2}$ Bacharel em Geografia

3 Professor adjunto do Departamento de Geografia, Coordenador do Laboratório de Biogeografia e Geografia da Saúde e Orientador da doutoranda Leonice Seolin Dias. 
famílias de moscas abordadas na pesquisa, visualização das principais características dessas famílias e, aplicação de um questionário final. Participaram da atividade 160 alunos do ensino fundamental e médio. Verificamos com essa experiência que atividades que envolvem a comunidade são de grande importância, pois estreitam a distância entre a pesquisa ciêntífica e as pessoas que habitam o espaço estudado. A confirmação disso foi o grande interesse dos alunos em aprender sobre os insetos que antes julgavam sem importância para o homem.

Palavras-chave: Geografia da Saúde. Moscas. Vetores de doenças. Saúde ambiental.

\section{INTRODUÇÃO}

O Laboratório de Biogeografia e Geografia da Saúde da UNESP, de Presidente Prudente (SP), foi criado para desenvolver estudos que correlacionam a saúde coletiva e os padrões espaciais de condição de vida. Sendo assim, o Laboratório tem o foco em problemas relacionados à saúde ambiental. Desde 2008, os estudos de vetores de doenças infecto-contagiosas aproximou a equipe do laboratório das pesquisas em zoogeografia.

Diante disso, o laboratório vem desenvolvendo pesquisas sobre a população de dípteros, uma vez que dentre os insetos que se adaptaram ao ambiente construído pelo homem destacam-se as moscas, pela sua diversidade de espécies, abundância populacional, curto ciclo reprodutivo e dificuldade de controle. Atualmente, está em andamento no município de Teodoro Sampaio (SP) um estudo sobre as moscas em ambientes naturais, agrícolas e urbanos (Projeto Biota, processo FAPESP: 2011/50314-6).

Os resultados preliminares desse estudo demonstraram a predominância da família Calliphoridae (950; 40,7\%), seguida da Fanniidae (822, 35,2\%), Sarcophagidae (419, $17,9 \%$ ) e Muscidae (145, 6,2\%). Em relação às estruturas parasitárias observadas em moscas capturadas no centro urbano e no assentamento rural, foram as mais frequentes: Giardia spp. (45 cistos; 23 na cidade e 22 em assentamento) e Entamoeba spp. (28 cistos; 25 na cidade e 03 no assentamento). Os califorídeos apresentaram o maior número de estruturas (41 cistos de Giardia spp. e 22 de Entamoeba spp.), enquanto os muscídeos veicularam quatro cistos de Giardia spp. e seis de Entamoeba spp. Verificou-se ainda dois 
oocistos não esporulados de protozoários em califorídeos, um para cada ambiente estudado (SEOLIN DIAS et al, 2013).

Os dípteros muscóides são considerados de grande importância pela sua capacidade de utilizarem diferentes meios como substratos para alimentação e para o desenvolvimento de suas larvas (D’ALMEIDA; D’ALMEIDA, 1998). Geralmente, são encontrados em estábulos de pecuária leiteira, abatedouros, frigoríficos, aviários, plantas em decomposição, carcaças de animais, curtimes, terrenos baldios, lixo doméstico, aterros sanitários e lixões, frutos caídos, entre outros (GUIMARÃES; PRADO; LINHARES, 1978; BORROR, DELONG, 1988).

As moscas são de grande importância não apenas do ponto de vista puramente ecológico por atuarem como polinizadores e ter uma participação notável no processo de decomposição de matéria orgânica, mas também devido à sua importância médicosanitária (LINHARES, 1979; SMITH, 1986). Esses insetos são potenciais vetores mecânicos de agentes etiológicos, tais como vírus, bactérias, cistos de protozoários e ovos de helmintos. Além disso, suas larvas podem causar infecções no homem e animais (GREENBERG, 1971).

As principais espécies relacionadas à transmissão de patógenos são as moscas sinantrópicas (POLVONY, 1971). A capacidade de adaptação desses insetos aos ambientes criados pelo homem é que dá a condição de serem consideradas sinantrópicas. A relação com esses ambientes ocorre pelo fato de que esses insetos são exploradores de substâncias e resíduos orgânicos produzidos pela atividade humana e animal, especialmente fezes e resíduos vegetais em decomposição (MONTEIRO, 1995).

As moscas são muito comuns em áreas rurais e urbanas. Nas urbanas, algumas espécies adaptaram-se bem às condições criadas pelo homem, enquanto outras não apresentaram tolerância ao processo de urbanização. Aparentemente inofensivas, porque a maioria das moscas não pica, são transmissoras de doenças ao homem e animais por estarem ligadas ao nosso cotidiano. Estão em todos os lugares: nas ruas, nas residências, entre outros ambientes; passam despercebidas aos nossos olhos; ou acabam sendo consideradas como membros da família (SEOLIN DIAS; GUIMARÃES, 2012).

Por outro lado, os insetos são considerados bons indicadores dos níveis de impacto ambiental devido à sua grande diversidade de especies e habitat, além da sua importância nos processos biológicos dos ecossistemas naturais (WINK et al., 2005). 
Sendo assim, a qualidade ambiental de um determinado local pode ser avaliada pela presença de certas espécies de moscas e a sua abundância, caracterizando-as como um indicador biológico (SEOLIN DIAS, FONSECA, GUIMARÃES, 2012). Segundo Paiva (2011), por se criarem no esterco, em carcaças e no lixo que apodrece, o aumento nas populações de dípteros muscóides são indicadores de que esses resíduos necessitam de destinação adequada.

Com os trabalhos de campo sendo realizados mensalmente no município de Teodoro Sampaio, proporcionava-se um vínculo de amizade dos pesquisadores com alguns moradores da cidade e do assentamento, o que despertava um interesse e ao mesmo tempo curiosidade com relação à pesquisa, principalmente por tratar-se das moscas, segundo os moradores, "insetos insignificantes".

Diante dos fatores apresentados, no evento municipal da Semana do Meio Ambiente realizado no mês de junho deste ano em Teodoro Sampaio, participamos da programação, com o apoio de alguns professores da rede publica, desenvolvendo uma atividade denominada "Circuito ciências", com a realização de um inquérito sobre a percepção entomológica dos estudantes, apresentação de vídeo sobre as moscas, imagens das principais famílias desses insetos, figuras com algumas características morfológicas e visualização dos insetos em placas de petri.

É importante destacar que:

[...] a educação em saúde consiste em proporcionar à população os conhecimentos e as destrezas necessárias para a promoção e proteção de sua saúde individual, da saúde de sua família e de sua comunidade, por meio do desenvolvimento de capacidades e habilidades para que as pessoas participem ativamente na definição de suas necessidades e consigam negociar e implantar suas propostas para a obtenção das metas de saúde (SEOLIN DIAS; GUIMARÃES, 2012 apud CERQUEIRA, 1997).

Ainda, segundo Pelicioni e Pelicioni (2007):

[...] a educação em saúde deve estar presente em todas as ações para promover a saúde e prevenir as doenças, facilitando a incorporação de ideias e práticas corretas que passem a fazer parte do cotidiano das pessoas de forma a atender suas reais necessidades. Essa atividade pode ser desenvolvida em espaços diversos, como escolas, por exemplo, permitindo a expansão e o fortalecimento da saúde da população através de um trabalho coletivo e participativo com toda a comunidade escolar. 
Sendo assim, para despertar nos alunos uma conscientização ambiental, torna-se necessário o desenvolvimento de projetos e atividades que propiciem a oportunidade de vivenciar e colaborar para a produção de um meio ambiente mais limpo e preservado, aliando teoria e prática (SEOLIN DIAS; GUIMARÃES, 2012).

Com base nestas informações, o presente trabalho tem como objetivo relatar a experiência sobre as atividades desenvolvida pelo Laboratório de Biogeografia e Geografia da Saúde da UNESP de Presidente Prudente - SP, denominada "Circuito Ciências", no evento municipal da Semana do Meio Ambiente, em junho de 2013, com apoio de alguns professores da rede pública do município de Teodoro Sampaio, SP.

\section{METODOLOGIA}

O munícipio de Teodoro Sampaio localiza-se no extremo oeste do Estado de São

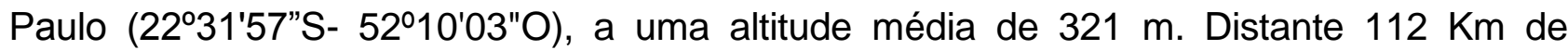
Presidente Prudente e $672 \mathrm{Km}$ da capital paulista, possui uma área total de $1.557 \mathrm{~km}^{2}$ e uma população de 21.386 habitantes, segundo dados do CENSO do IBGE (2010). O município possui uma reserva ambiental de Mata Atlântica denominada "Parque Estadual Morro do Diabo", que se distancia do centro urbano cerca de $10 \mathrm{~km}$. Sua economia está baseada no setor terciário, que compreende atividade comercial, e setor primário, com destaque para a criação de pecuária de corte e leiteira. Nos últimos 10 anos, o meio rural do município tem sofrido profundas mudanças com a expansão da cultura canavieira por grandes empresas do agronegócio.

Na Semana do Meio Ambiente, de 04 a 06 junho de 2013, em Teodoro Sampaio, a Divisão do Meio Ambiente do município organizou um evento para comemorar a data no clube Taquaruçu. Além da participação da Secretaria da Cultura, colaboraram no evento o Parque Estadual do Morro do Diabo, o Instituto de Pesquisas Ecológicas (IPÊ) e o Laboratório de Biogeografia e Geografia da Saúde da UNESP de Presidente Prudente (SP)(Figura 1). 


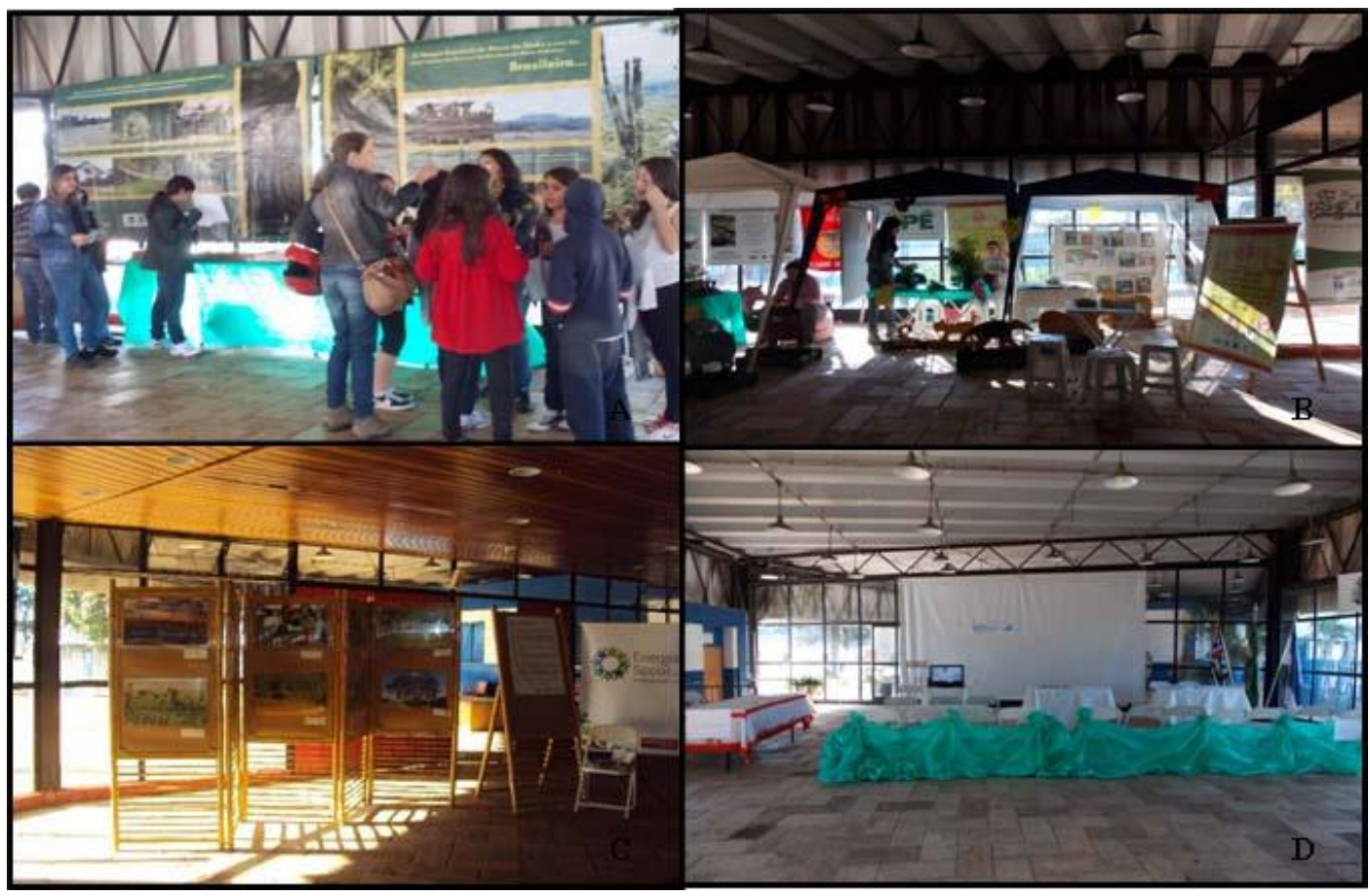

Figura 1: Interior do clube Taquaruçu antes da realização da programação: a) Espaço destinado ao Parque Estadual do Morro do Diabo; b) ao Instituto de Pesquisas Ecológicas (IPÊ) c) ao Projeto energia solar e d) ao Laboratório de Biogeografia e Geografia da Saúde da UNESP de Presidente Prudente (SP). Fonte: os autores (jun. 2013).

O estudo a respeito da frequência de moscas sinantrópicas em ambientes naturais (unidade de preservação ambiental), ambiente rural e urbano está sendo utilizado como parâmetro do impacto destas transformações na saúde ambiental. Os dados levantados na pesquisa do Laboratório foram utilizados para a organização do circuito de ciências. Dessa forma, o Circuito Ciências apresentou as seguintes atividades: 1) realização de um inquérito sobre a percepção entomológica dos estudantes; 2) apresentação de vídeo sobre as moscas, 3) imagens das principais famílias de dípteros muscóides, 4) figuras com algumas características morfológicas, visualização dos insetos em placas de petri e 5) realização de um segundo questionário, para os alunos do ensino médio, intitulado "A importância das moscas para a saúde".

$O$ registro dos dados de como os alunos percebem e interagem com os insetos ocorreu por meio da aplicação de um formulário semiestruturado, constituído de oito perguntas: "Cite exemplos de insetos que você conheça"; "Por que você acha que esses animais (que você exemplificou) são insetos?"; "Qual a importância dos insetos?"; "Você 
acha que ficou doente por causa de algum inseto? Qual doença?"; Como você sabe disso?"; "Quando você vê uma mosca, quais as três palavras que surgem em sua mente?"; "Quais os tipos de moscas que você conhece?"; "O que você acha que deve ser feito para eliminar as moscas?". Já o segundo questionário constituído de quatro perguntas: "As moscas se desenvolvem em que tipo de ambiente?"; "Qual a importância ecológica das moscas"; Por que a disseminação pode ser transformar num problema de saúde pública" e "Descreva as moscas de acordo com as famílias, considerando as classes das fichas. Em quantos grupos podemos observar as moscas do recipiente?"

Para fins de análise dos resultados obtidos em campo, a tabulação dos dados foi realizada com o auxílio do software Microsoft Excel e ocorreu de forma quanti-qualitativa.

\section{RESULTADOS E DISCUSSÃO}

O recinto do clube Taquaruçu recebeu um número expressivo de estudantes das escolas da rede pública desde a pré-escola até o ensino médio, que foram trazidos ao local do evento por meio do transporte público juntamente com seus respectivos professores (Figura 2). O espaço destinado às atividades do "Circuito Ciências" também recebeu a presença de muitos estudantes.

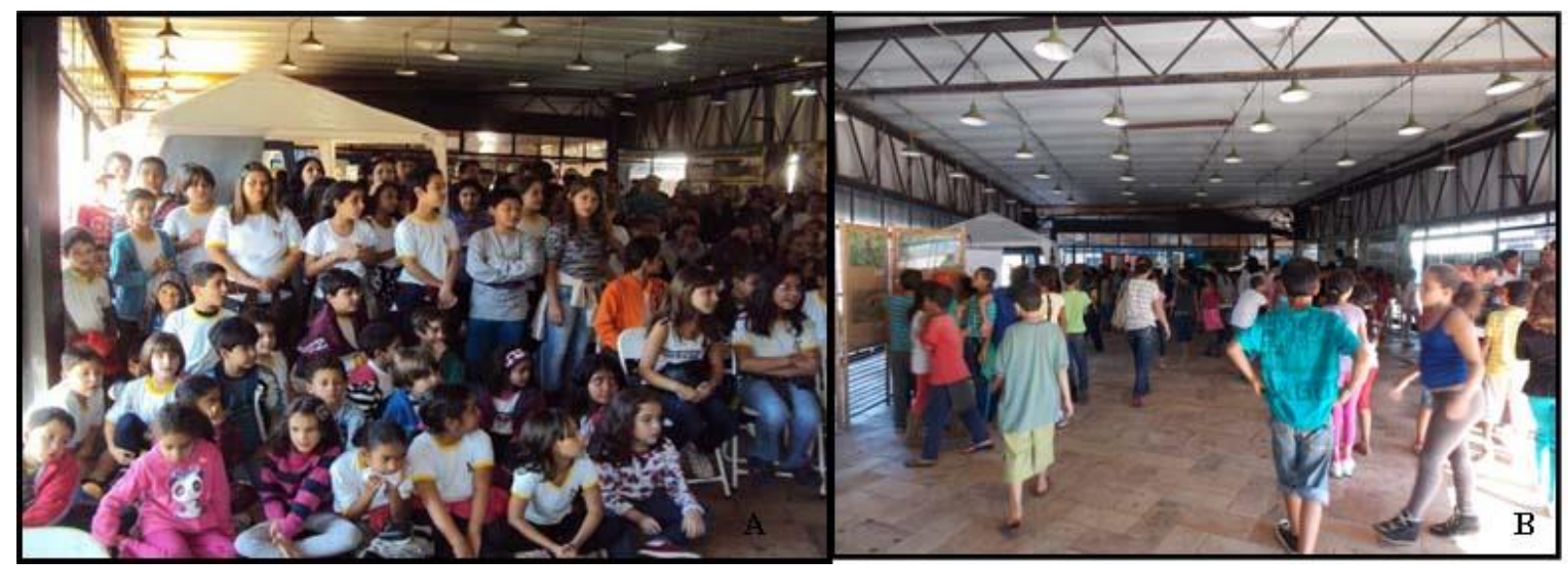

Figura 2. No clube Taquaruçu em Teodoro Sampaio (SP): A e B) os estudantes no interior do recinto. Fonte: os autores (jun. 2013). 
O primeiro procedimento do "Circuito Ciências" foi o preenchimento dos questionarios pelos estudantes. Para isso foi colocada uma mesa na entrada do espaço para que os participantes pudessem responder em grupo de aproximadamente 08 a 10 pessoas. O intuito desse primeiro questionário era examinar a percepção entomólogica de alguns estudantes presentes no recinto (Figura 3).

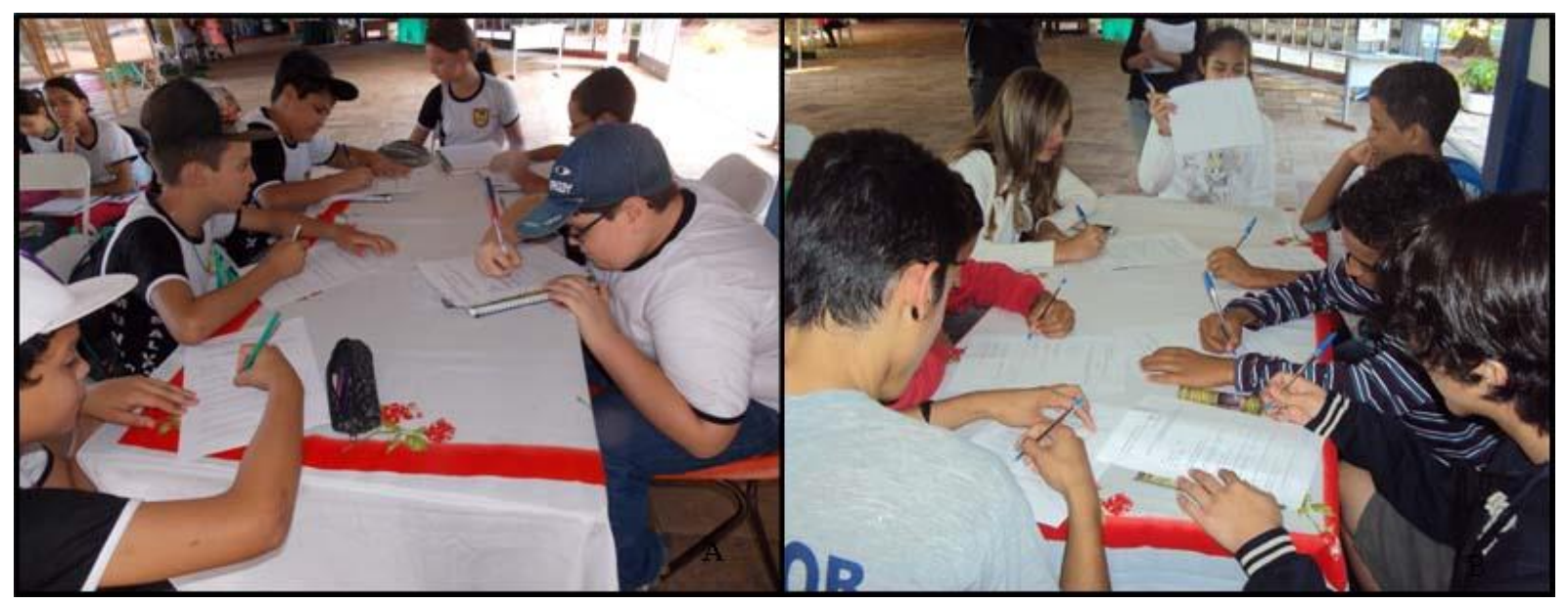

Figura 3: Preenchimento do questionários: a) estudantes do ensino fundamental e b) ensino médio. Fonte: os autores (jun. 2013).

O vídeo, com duração de cinco minutos, foi a segunta atividade proposta pelo circuito. Para isso foi organizado um espaço com cadeiras enfileiradas e o vídeo foi apresentado em um computador transportado até o clube. O vídeo buscou abordar os ciclos de desenvolvimento dos dípteros e sua inserção na cadeia ecológica, como por exemplo: os principais ambientes em que frequentam, tipo de alimentação, seu papel de decompositor de matéria orgânica e vetores mecânicos de patógenos. O material composto por imagens animadas atraiu a atenção dos estudantes, principalmente pelas aquelas sobre a decomposição (Figura 4).

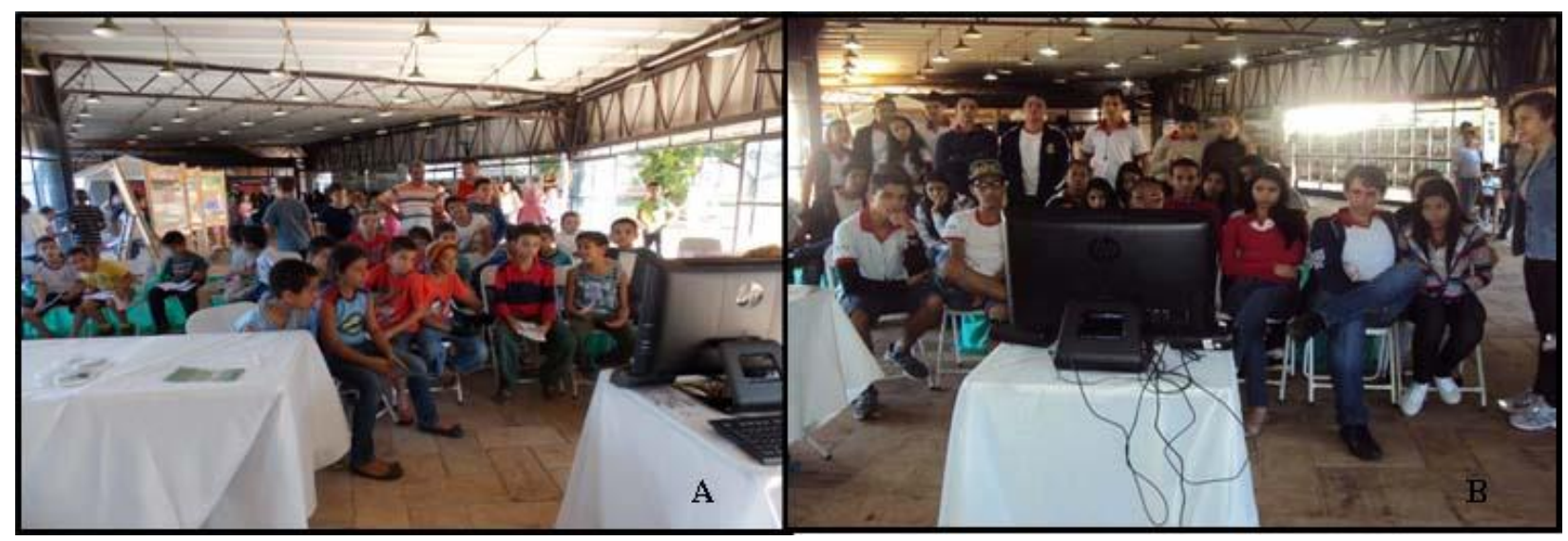


Figura 4: Momento da apresentação do vídeo: a) alunos do ensino fundamental e b) estudantes do ensino médio. Fonte: os autores (jun. 2013).

A terceira etapa consistiu na visualização em placas de petri das famílias de dípteros muscóides trabalhadas no circuito: Calliphoridae, Fanniidae, Sarcophagidae e Muscidae, juntamente com uma explicação de suas principais características e diferenças entre elas. Para tanto, organizamos duas mesas para que pudessem ser expostas as placas de petri, vedadas com fita adesiva, com algumas moscas mortas, para que os participantes pudessem manuseá-las (Figura 5).

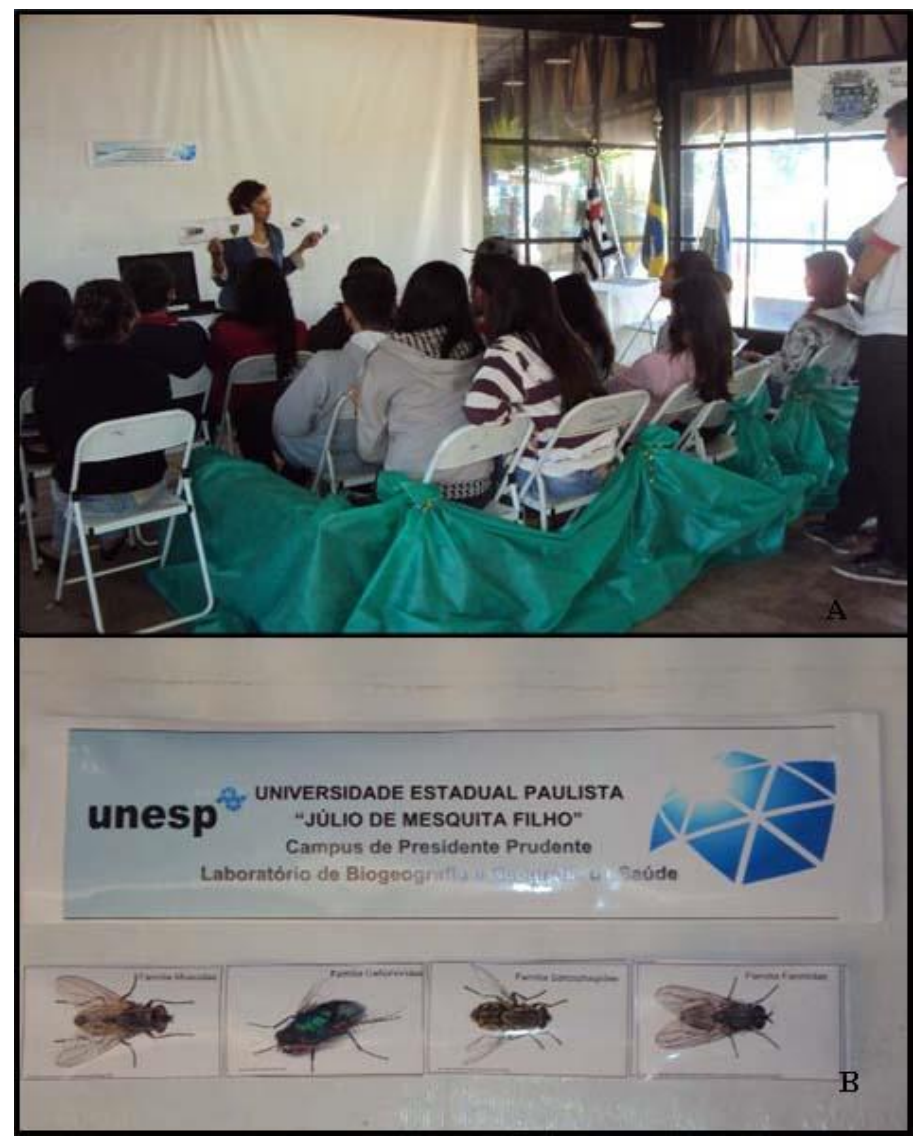

Figura 5. A) Um dos momentos de exposição de figuras dos principais caracteres morfológicos dos insetos, b) figuras das famílias de moscas Muscidae, Calliphoridae, Sarcophagidae e Fanniidae. Fonte: os autores (jun. 2013). 


\section{Sans}

ISSN 1980-0827

Volume 9, Número 6, 2013

Esse momento proporcionou um contato com os insetos, em que os estudantes puderam manusear as placas de petri e observar em curta distância os que são tão ágeis no dia a dia e por isto dificulta essa observação.

Como complemento dessa atividade, as análises das principais características das moscas em figuras teve a intenção de que os estudantes pudessem analisar as imagens e, em grupo, identificar as principais características de cada família na placa de petri (Figura 6). Essa atividade permitiu que os participantes aprendessem a diferenciar as quatro moscas e tirar suas dúvidas ao longo da exposição, em específico de cada família.

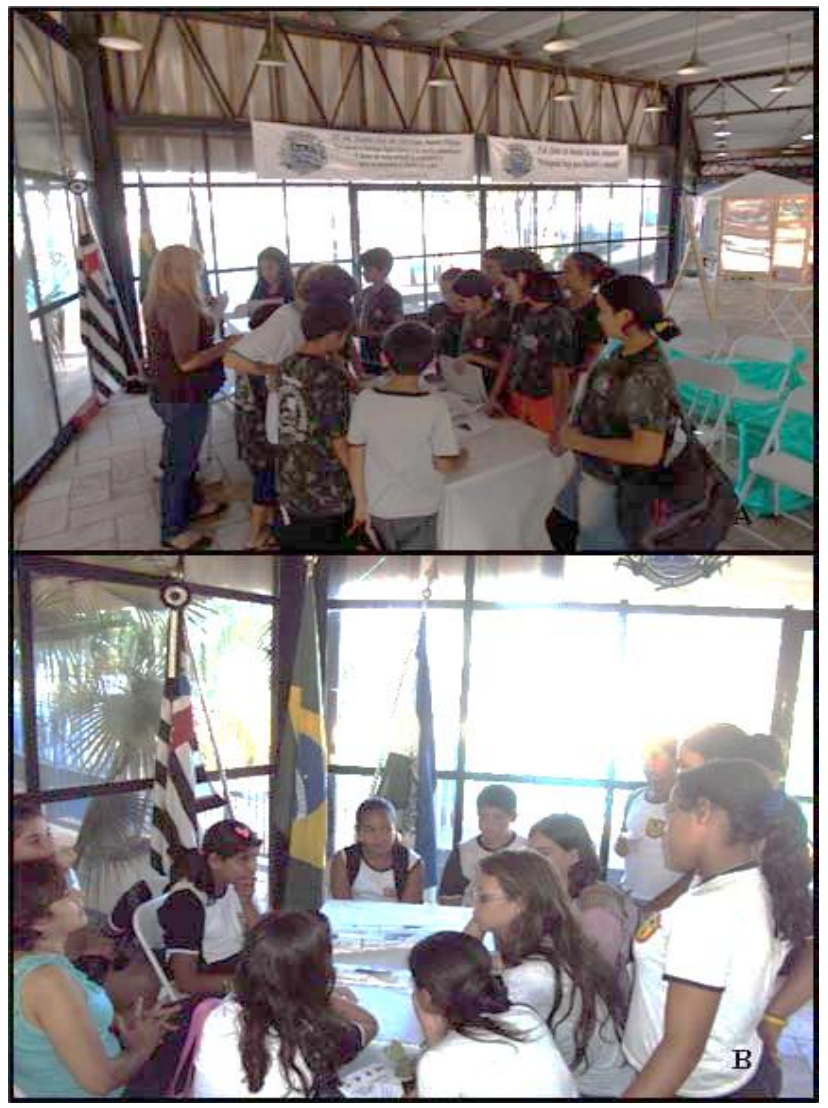

Figura 6. Manuseio das figuras das moscas e das placas de petri com alguns insetos, pelos estudantes. Fonte: os autores (jun. 2013).

Vale a pena mencionar que os estudantes que visitaram o clube puderam, ainda, receber mudas de árvores; apreciar alguns animais empalhados do pequeno museu do Parque Florestal e ver a exposição de fotográfias sobre o plantio de cana-de-acuçar da Escola Tecnica (ETEC) (Figura 7). 


\section{trom

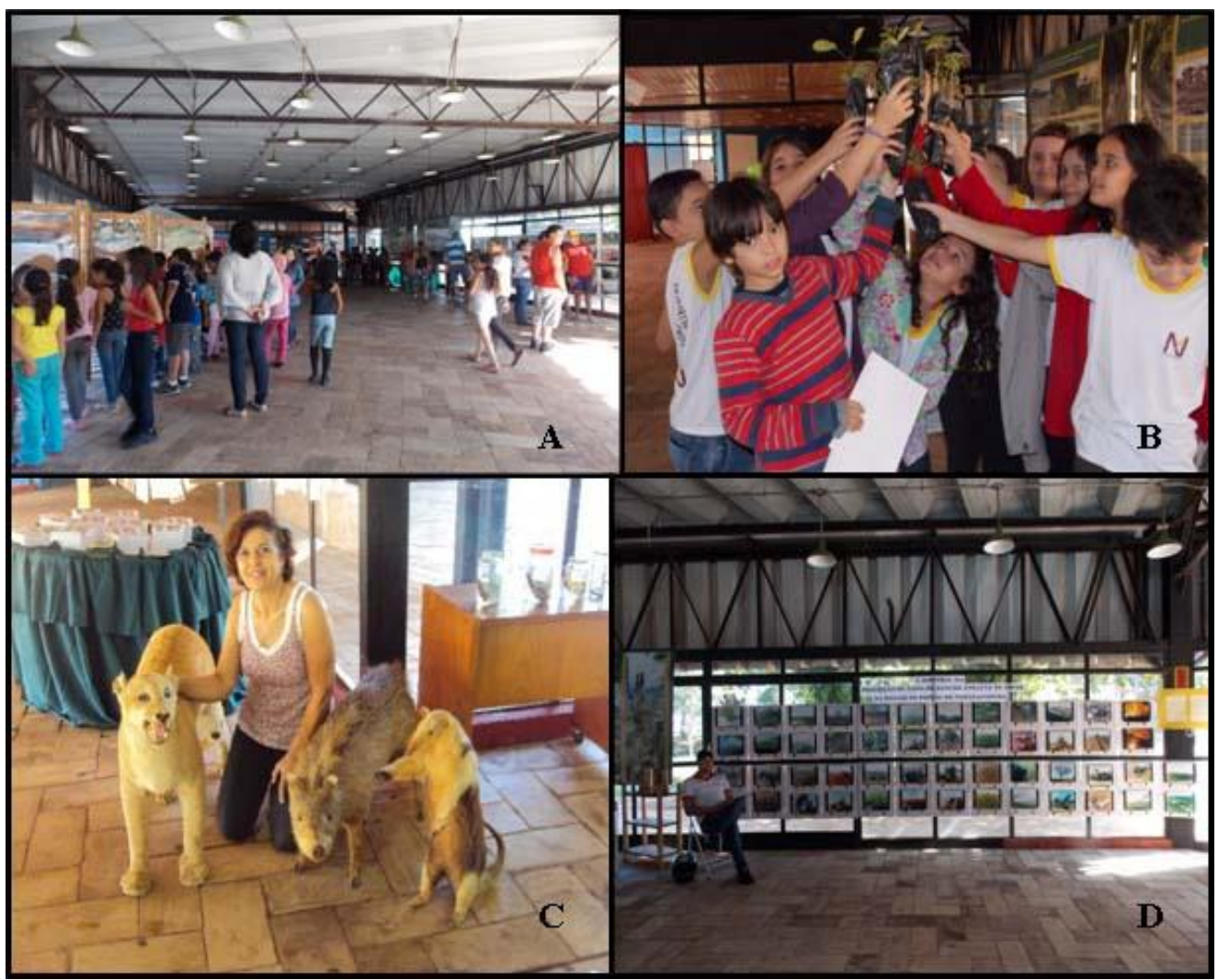

Figura 7. No interior do clube Taquaruçu: A) Exposição da reciclagem de óleo; b) Mudas de árvores doadas para os estudantes; c) Alguns animais empalhados, do Museu do Parque Florestal e D) Exposição de fotografias sobre o plantio de cana-de-açúcar da ETEC. Fonte: os autores (jun. 2013).

\section{CONSIDERAÇÕES FINAIS}

A atividade denominada "Circuito Ciencias", apresentada na semana do Meio ambiente em Teodoro Sampaio pelo Laboratório da UNESP, foi relevante uma vez que possibilitou o retorno da pesquisa científica realizada no município à sociedade, através do esclarecimento aos alunos sobre a importância ecológica das moscas, os quais se mostraram interessados com a elucidação e obtiveram, ao final, um maior conhecimento sobre a temática. O estudo da percepção a respeito de animais reconhecidos como "insetos" e as moscas, em particular, revela aspectos importantes que devem ser considerados nas medidas de monitoramento e controle de vetores de doenças, possibilitando observar que a tendência dos alunos frente às primeiras reações à mosca é de espantá-las e não matá-las. Possivelmente, tal fato pode estar relacionado a característica rural do município e à presença de insetos diversos, entre eles as moscas, 
nos quintais residenciais. A mosca varejeira aparece como a mais mencionada pelos estudantes, seguida pela mosca doméstica. E, para a eliminação das moscas o modo de efeito é por meio da utilização de produtos químicos.

\section{REFERÊNCIAS}

BORROR, D., DELONG, D. M. Introdução ao Estudo dos Insetos. São Paulo: Edgard Blücher, 1988, $653 \mathrm{p}$.

CERQUEIRA, M. T. Promoción de la salud y educación para la salud: retos y perspectivas. Anais... Organización mundial de la salud. La promoción de la salud y la educación para la salud en América Latina: un análisis sectorial. Genebra: Editorial de La Universidad de Puerto Rico, 1997. p. 7-48.

D'ALMEIDA, J. M.; ALMEIDA, J. R. Nichos tróficos em dípteros caliptrados no Rio de Janeiro, RJ. Revista Brasileira de biologia, v. 58, n. 4, p. 569-570; 1998.

GREENBERG, B. Flies and diseases. Ecology, classification and biotic association. Princeton: Princeton University, 1971. 856 p.

GUIMARÃES, J. H.; PRADO A. P.; LINHARES, A. X. Three newly introduced blowflies species in southern Brazil (Diptera: Calliphoridae). Revista Brasileira de Entomologia, v. 22, p.53-60, 1978.

IBGE - Instituto Brasileiro de Geografia e Estatística. Disponível em:

<http://www.ibge.gov.br/cidadesat/painel/painel.php?codmun=355430>. Acesso em set. 2013.

LINHARES, A. X. Sinantropia de dipteros muscóides de Campinas. 1979. 129 p. Dissertação (Mestrado Ciências Biológicas) - Universidade Estadual de Campinas, Campinas, São Paulo, 1979.

MONTEIRO, M R. Microhimenópteros (Insecta: Hymenoptera) parasitóides e insetos predadores de moscas sinantrópicas (Insecta: Diptera) na Granja Capuavinha, Monte-Mor, SP. 1995. 99 p. Dissertação de mestrado, UNICAMP, Campinas.

PAIVA, D. P. As moscas como indicadores biológicos da alteração ambiental. Disponível em: <http://www.cnpsa.embrapa.br/pnma/pdf_doc/6-Dora-moscas.pdf> . Acesso em: 15 out. 2013.

PELICIONI, M. C. F.; PELICIONI, A. F. Educação e promoção da saúde: uma retrospectiva histórica. $\mathbf{O}$ mundo da saúde, São Paulo: v. 31; n. 3, p. 320-328, 2007.

POVOLNÝ, D. Synanthropy flies and disease, ecology, classification, and biotic associations. Princeton Univ. Press.Princeton. N. J., p. 17-54, 1971. 
SEOLIN DIAS, L.; FONSECA, E. S.; GUIMARÃES, R. B. Distribuição espacial de moscas sinantrópicas (Insecta, Díptera) no Campus da UNESP de Presidente Prudente, SP. Revista GeoAtos, v. 1, n. 12, p. 43-53, 2012.

SEOLIN DIAS, L.; GUIMARÃES, R. B. Moscas sinantrópicas: uma contribuição para a educação ambiental no município de Teodoro Sampaio, São Paulo. Anais... 14 Encontro de Geógrafos da América Latina, Lima, Peru. Disponível em: <ttp://www.egal2013.pe/wpcontent/uploads/2013/07/Tra_Leonice-Raul.pdf> Acesso em: 15 set. 2013.

SEOLIN DIAS, L. et al. Estruturas parasitárias veiculadas por moscas em quatro biótopos de Teodoro Sampaio, São Paulo, Brasil. Anais... XXIII Congresso Brasileiro de Parasitologia e III Encontro de Parasitologia do MERCOSUL. CD-ROM.

WINK, C.; GUEDES, J. V. C.; FAGUNDES, C. K.; ROVEDDER, A. P. Insetos edáficos como indicadores da qualidade ambiental. Revista de Ciências Agroveterinárias, Lages, v. 4, n.1, p.60 -71, 2005.

SMITH, K. G. V. A Manual of Forensic Entomology . Ithaca:Comstock Publishing Associates, 1986, $205 \mathrm{p}$. 